International Journal of

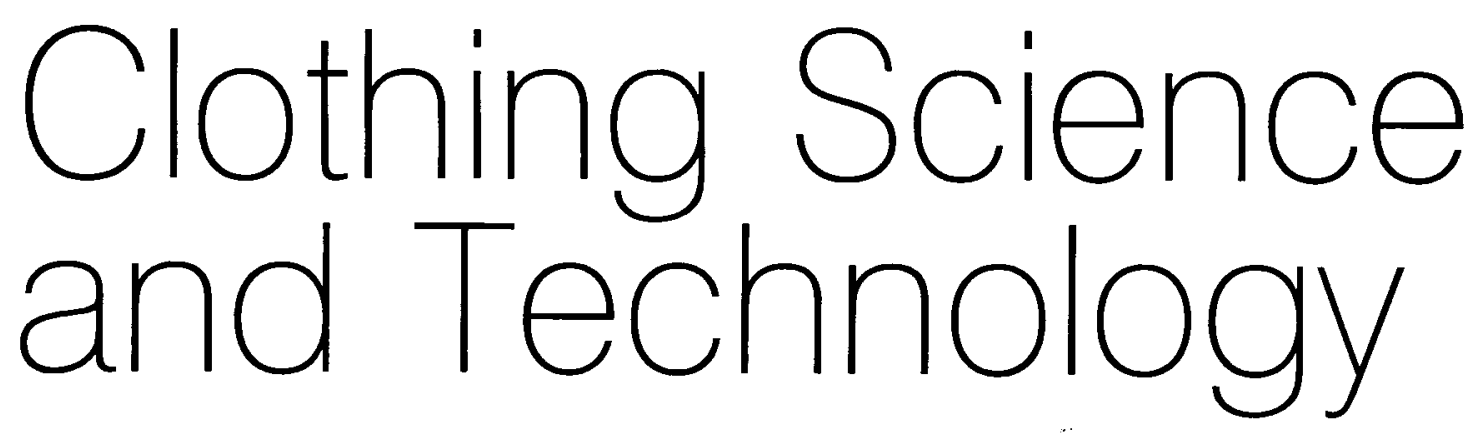

\title{
Designing surgical clothing and drapes according to the new technical standards
}

\author{
M.J. Abreu \\ Departamento de Engenharia Têxtil, Universidade do Minho, Guimarães, Portugal \\ M.E. Silva \\ Departamento de Engenharia Têxtil, Universidade do Minho, Guimarães, Portugal \\ L. Schacher \\ Ecole Nationale Supérieure des Industries Textiles de Mulhouse, Mulhouse, Cedex, France \\ D. Adolphe \\ Ecole Nationale Supérieure des Industries Textiles de Mulhouse, Mulhouse, Cedex, France
}

\section{Emerald}

International Journal of Clothing Science and Technology, Vol. 15 No. 1, 2003 ,

(C) MCB UP Limited, $0955-6222$ 


\title{
COMMUNICATIONS \\ Designing surgical clothing and drapes according to the new technical standards
}

Designing surgical clothing and drapes

\author{
M.J. Abreu and M.E. Silva \\ Departamento de Engenharia Têxtil, Universidade do Minho, \\ Guimarães, Portugal \\ L. Schacher and D. Adolphe \\ Ecole Nationale Supérieure des Industries Textiles de Mulhouse, \\ Mulhouse, Cedex, France
}

Keywords Protective clothing, Performance, Medical

\begin{abstract}
Hospitals will continue to be the largest consumers of disposables, because of the diverse range of procedures they provide. Favourable growth is forecast for non-wovens. Increasing concern over contamination and nosocomial infections will boost the demand for consumable and disposable surgical gowns and drapes. But, until now neither the manufacturers nor the end users of surgical gowns and drapes could agree on standards. So, a mandatory European standard is being developed to establish basic requirements and test methods for disposable and reusable materials used for surgical gowns and drapes. Once this standard has been adopted, the continued use of cotton textiles and conventional cotton-polyester mixed textiles will become questionable.
\end{abstract}

\section{Introduction}

According to the Medical Device Directive $93 / 42 / \mathrm{EEC}$, surgical clothing, drapes and air suits are considered to be medical devices, whether they are reusable or disposable gowns and drapes.

Medical products are divided into four classes: I, IIa, IIb and III. The classification is in accordance with Annex IX of the Directive. All non-invasive medical products are class I. This way surgical gowns and drapes are medical devices of class I. Only the abdominal towels as invasive products belong in class IIa (Werner, 2000).

This Directive on medical devices is the basis for evaluating surgical materials and has been transformed into national law since 14 June 1998 by appropriate regulations in all the European member countries.

As part of these legal specifications, CEN (European Committee of Standardisation) has requested that a working group in 1996 (TC 205/WG 14) should develop a standard for these directives.

The proposed mandatory European standard "surgical drapes, gowns and clean air suits, used as medical devices, for patients, clinical staff and equipment", is being developed by the Technical Committee TC 205

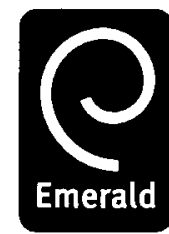

International Journal of Clothing Science and Technology Vol. 15 No. 1, 2003 (c) MCB UP. $69-74$ 0955-6222 
Requirements for medical gloves are given in the EN 455 and packaging materials are covered by the EN 868 .

Requirements for surgical masks and head coverings will be specified in future CEN/TC 205 standards (CEN, 2001).

\section{Surgical drape, gown and clean air suit materials}

Cotton textiles or conventional mixed cotton-polyester textiles, the traditional materials for surgical gowns and drapes, meet a number of requirements, such as comfort, drapeability, good tensile strength, steam permeability and steam sterilisability. However, they will not meet the requirements of the new standard which includes resistance to microbial penetration, resistance to liquid penetration and minimal release of particles.

Cotton containing gowns and drapes must be replaced and the future looks bright for quality, properly processed reusable products or quality single-use disposable products (Patel et al, 1998).

There is a wide variety of non-wovens of all types including hydroentangled, bonded, stitched, and laminated, of a range of quality depending on the intended use by the manufacturer. There are also combinations of various fabrics in one product and there are reusables which range from basic cotton and polyester/cotton weave fabrics, to micro-filament, micro-weave polyester (Mounter, 1999).

Various single-use products and reusable materials have been proposed for surgical gowns and drapes with the objective of reducing microbial contamination of the incision and protecting the operating room staff from infection. However, this is not concerned about the user awareness.

At present, producers and users are not getting enough information about the suitability of the materials used in surgery.

In the interest of patient and personnel protection, identical requirements must be applied to single-use products and to reusable surgical materials.

\section{Surgical gowns}

These products are used in the operating theatre to prevent transfer of infective agents.

\section{Surgical drapes}

These products are used in the operating theatre to cover the patient and equipment to protect them from pollutant particles in the air, which carry infective agents.

\section{Clean air suits}

These products intended to minimise contamination of the operating wound by the wearer's skin scales carrying infective agents via the operating room air thereby reducing the risk for wound infection. 
IJCST

15,1

72

Requirements for surgical gowns

\section{Surgical drape and gown requirements}

There are a number of factors that need to be considered to determine what type of textile to use in the operating theatre, which will be based on a number of various, perhaps competing priorities:

\section{Performance requirements}

Other general requirements for surgical drapes and gowns include aesthetics (including conformability, tactile softness, and comfort), fibre tie-down properties (linting and abrasion resistance), flame resistance, static safety and toxicity (Tables I and II).

For surgical drapes, stiffness is very critical because the barrier performance could affect the conformability to patient or equipment.

As to gowns, comfort and stiffness may affect perspiration and movement. Strength requirements include tensile, tear, burst and puncture resistance. Linting has to be avoided, because particles from gown or drape may complicate the wound healing process. Good abrasion resistance is a basic requirement for the safety of barrier materials. Flame and electrostatic resistance is needed especially for laser applications and oxygen administration, because of the danger of explosion (Adanur, 1995).

Resistance to microbial penetration - dry

Resistance to microbial penetration - wet

Cleanliness - microbial

Cleanliness - particulate matter

Linting

Resistance to liquid penetration

Bursting strength - dry

Bursting strength - wet

Tensile strength - dry

Tensile strength - wet

Resistance to microbial penetration - dry

Resistance to microbial penetration - wet

Cleanliness - microbial

Cleanliness - particulate matter

Linting

Resistance to liquid penetration

Bursting strength - dry

Bursting strength - wet

Table II. Tensile strength - dry

Requirements for Tensile strength - wet surgical drapes
Adhesion for fixation for the purpose of wound isolation 
The resistance to microbial penetration is important for both products and in a hospital you can find micro-organisms in the air and in liquids (for example in the blood of the patient). The sizes of the solid particle, bacteria and viruses are $10-40,0.5-20$ and $0.01-0.3 \mu \mathrm{m}$, respectively.

\section{Designing surgical clothing and drapes}

Type of surgical procedure

Some procedures are very invasive with large amounts of body fluids involved 73 and some are regarded as highly risky, such as Orthopaedic and Neurosurgery; others, perhaps less invasive, are regarded as lower risk. It is the responsibility of the end users to determine what fabrics they wish to use and for which surgical procedures. The user endorses the responsibility not to use fabrics for which they were never intended (Mounter, 1999).

In the actual operating area, a covering material must be used which presents an adequate barrier throughout the entire duration of the operation, even under mechanical pressure. The same requirement for the protection of the patient must be placed to the same extent on surgical gowns for the protection of the personnel. This concerns the areas, which are exposed to mechanical pressure or liquid as, for example, the front of the gown and the sleeves up to the elbow.

Every operation is associated with certain risks of contamination. The medical success of a procedure can be especially affected by post-operative infections.

A post-operative infection depends on numerous factors such as the duration of the operation, the operation technique, the mechanical pressure and the patient's vulnerability to infection (Werner, 2000).

\section{Processing requirements}

The primary purpose of sterilising an item is to render it safe for use by destroying all living microscopic organisms. Because bacteria multiply very quickly, the sterilisation process must be absolute. Even a few organisms invading the patient's body during a surgical procedure can reproduce rapidly and contribute to post-operative complications.

Four common types of sterilisation are in use today: gas, irradiation, steam autoclave and dry heat. The first two types of sterilisation are also called low temperature sterilisation methods, applied to single-use products and the last two types, high temperature sterilisation methods, applied to reusable products (Araújo Marques, 1997).

The traceability of decontamination, disinfection and sterilisation shall be maintained. The properties of the materials will have to be maintained using the agreed processing or the other procedures that can maintain the properties of the material. A processing specification will have to be designed and validated for the product, including visual and hygienic cleanliness, decontamination, disinfection and sterilisation (Werner, 2000). 

IJCST
15,1
74
Costs
In Europe, 30 million operations are performed every year. Assuming that the cost of one surgical infection in Europe amounts to 2,500 Euros, 1 per cent reduction in the surgical infection rate saves 748 million Euros each year. So we can safely assume that the reduction of post-operative infection would generate considerable savings.

\section{Conclusions}

Users of surgical gowns and drapes can continue to use whatever type of textile product they wish, although they do have a responsibility to take manufacturers claims for their products into account and not to use devices for purposes for which they were never intended. The Medical Device Regulations do not prevent the surgical staff from using whatever type of textile they wish. Only if there is good collaboration between users, producers and hygienists, the creation of standards will succeed.

From the medical point of view, the protection of the patient and that of the personnel must be equally guaranteed whether single-use materials or reusable medical products are concerned. Neither reusable materials nor single-use products can generally be designated as suitable or unsuitable.

We acknowledge that there is possible difference between degrees of exposure between very minor and exploratory surgery and very major and open surgery, but we do not consider "medium" risks. Directive 93/42/EEC relating to medical devices identified that, although the emphasis on standards varies from country to country, the essential requirement of any product is to provide a high level of protection.

It is the responsibility of hospitals to ensure optimal protection of patients and users. In a lawsuit, this could lead to the burden of proof being shifted to the hospital, with the risk of liability. Because of this risk alone, the question of what surgical materials to use in the future is going to take up extreme significance.

\section{References}

Adanur, S. (1995), Wellington Sears Handbook, Technomic Publishing, USA.

Araújo Marques, MJ. (1997), "Contribuição para a definição de propriedades de materiais têxteis hospitalares descartáveis", Masters thesis.

CEN/TC 205/WG 14, (2001), "prEN 13795: surgical drapes, gowns and clean air suits, used as medical devices, for patients, clinical staff and equipment - Part 1", General Requirements for Manufacturers, Processors and Products.

Mounter, S. (1999), "Enforcing medical device regulations for medical textiles", Index 99 Congress-Medical Session, 27-30 April, Geneve, Switzerland.

Patel, S.R., Urech, D. and Werner, H.P. (1998), "The surgical gowns and drapes of tomorrow", Medical Device Technology, September 1998.

Werner, H.P. (2000), "The standardisation of hospital textiles and hygiene aspects of hospitals", FiberMed 2000 Conference, 12-14 June, Tampere, Finland. 